\title{
Assessment and Analysis on Land Ecological Risk of Jinshi City in Hunan Province
}

\author{
Dehua Mao ${ }^{1}$, Feng Wü${ }^{2}$, Ruizhi Guo ${ }^{3}$ \\ ${ }^{1}$ College of Resources and Environmental Sciences, Hunan Normal University, Changsha 410081, \\ China \\ ${ }^{2}$ Shenzhen-Hongkong Institute of Environmental Sciences of Shenzhen City, Shenzhen 518071, China \\ ${ }^{3}$ College of Mathematics and Statistics, Hunan Normal University, Changsha 410081, China
}

\section{湖南省津市市土地生态风险评价及分析 \\ 毛德华 ${ }^{1}$, 吴锋 ${ }^{2}$, 郭瑞芝 ${ }^{3}$ \\ ${ }^{1}$ 湖南师范大学资源与环境科学学院, 长沙 410081, 中国 \\ ${ }^{2}$ 深圳市深港环境科学研究院, 深圳 518071, 中国 \\ ${ }^{3}$ 湖南师范大学数学与统计学院, 长沙 410081 , 中国}

\begin{abstract}
Taking the database of land use current situationin Jinshi City as the information source, the unit grid of $1 \mathrm{~km} \times 1 \mathrm{~km}$ of whole Jinshi City is constructed through the processing and conversion of the database by using ArcGIS. The comprehensive ecological risk index in the unit grid is established based on the land use type of the whole city, and then the spatial differentiation characteristics and the causes of the land ecological risk in Jinshi city are revealed by using the spatial analysis method. The results show that the development pattern of town and along traffic trunk has a significant influence on land ecological risk.
\end{abstract}

Keywords: Land ecological risk; The comprehensive ecological risk index; Spatial differentiation; Jinshi City

\section{摘要}

以津市市土地利用现状数据库为信息 源, 以津市市全域为研究对象, 通过对土地 利用现状数据库的处理和转换, 利用 ArcGIS 对矢量图层构建出 $1 \mathrm{~km} \times 1 \mathrm{~km}$ 的单元网格, 基于全市的土地利用类型建立采样网格内 的综合生态风险指数, 然后利用空间分析方
法, 揭示津市市土地生态风险的空间分异特 征及其成因。研究结果表明, 城镇与沿交通 干线的发展模式对土地生态风险影响显著。 关键词: 土地生态风险; 综合生态风险指数; 空间分异; 津市市

关于土地生态风险, 迄今尚未形成明确 统一的定义。基于生态风险的概念 ${ }^{[1-2]}$, 土地 生态风险可认为是由于自然或人为原因致 使土地资源破坏或污染而对人类生存环境 造成的一种危害状态, 在这种状态下, 土地 生态系统没有稳定、均衡、充裕的自然资源 可供人类利用，土地资源不能维持环境与人 类的协调发展 ${ }^{\left[{ }^{[3]}\right.}$ 。可以将土地生态风险概念 的认识概括为以下几点 ${ }^{[4]}$ : (1) 生态风险表 现为生态系统受到外界威胁或胁迫的可能 性。(2) 土地生态风险是面向土地利用活动 的, 土地利用作为生态风险的风险源。(3) 生态系统一旦受到外界干扰, 其健康将遭受 不同程度的危害, 这种危害在生态系统的结 构和功能方面会有所表现。(4) 这里的生态 系统不仅是自然生态系统, 而且是由人类的 社会经济活动和自然条件共同组合而成的 社会一经济一自然复合生态系统。

土地生态风险评价在于揭示土地利用 风险因素导致的不良后果的程度及可能性。 土地生态风险评价涉及到环境学、生态学、 地理学、生物学等多学科的知识, 并且还需 
要采用统计学等风险分析以及遥感、GIS 等 先进的空间分析技术来预测、分析和评价具 有不确定性的风险因素对生态系统及其组 分可能造成的危害。土地生态风险评价可以 分为土地利用风险综合评价和土地利用专 项评价 (主要为土地整理生态风险评价)。

目前对于土地生态风险评价的研究是 基于多种学科交叉和数理统计手段以及 $3 \mathrm{~S}$ 等先进空间分析技术等来进行, 目的在于建 立起区域土地利用与生态风险之间的经验 关系, 主要研究重点在于定量研究 ${ }^{[5-12]}$ 。目前 土地生态风险评价方法主要分 2 类, 一类是 计算土地生态风险指数, 又可分为基于景观 结构的土地生态风险指数和基于土地利用 变化的土地生态风险指数; 二类是构建指标 体系, 采用诸如主成分分析法、层次分析法、 地统计学方法等进行综合评估。本文采用一 类方法, 建立不同土地利用类型与生态风险 度的关系, 特别之处在于运用 GIS 技术手段, 细致刻画 $1 \mathrm{~km} \times 1 \mathrm{~km}$ 的单元网格的土地生态 风险指数, 然后利用地统计分析模块, 对津 市市土地利用进行生态风险分析。

土地生态风险源主要可以归结为自然 和人为两类因素: 自然因素主要是气候、水 文、地质等方面的自然灾害。津市市的主要 自然灾害包括洪涝、干旱、冰冻、地质灾害 等; 人为因素引起的生态风险在津市市主要 表现为人类经济活动造成的水质污染、土壤 污染、植被破坏等, 同时一些不合理的土地 利用方式造成了部分地区土地退化、水土流 失、森林破坏、水域和湿地的占用及污染等 等, 这些会给人们生活和农田生态系统带来 较大的影响。一个区域的土地生态风险往往 受到多种因素的影响, 但是如果对所有影响 土地生态系统的自然或人为因素进行生态 风险评价是不切实际的, 也是没有必要的, 关键是有所侧重, 只有对那些能够给生态系 统和人类带来重大生态负效应的风险对象 进行生态风险评价和对策研究才真正具有 现实意义。

\section{1. 研究方法}

本文以津市市土地利用现状数据库 (第 2 次土地利用现状调查) 为信息源, 以全市 $558.35 \mathrm{~km}^{2}$ 区域为研究对象, 通过对土地利
用现状数据库的处理和转换, 利用 ArcGIS 对矢量图层构建出 $1 \mathrm{~km} \times 1 \mathrm{~km}$ 的单元网格, 并在此网格基础上基于全市的土地利用类 型建立采样网格内的综合生态风险指数, 然 后利用空间分析方法, 对津市市土地生态风 险的空间特征进行研究。在确定土地类型时, 参照中国《土地利用现状调查技术规程》, 并结合全市的土地利用实际情况, 在研究目 的的指导下将津市市整个区域各种用地分 为耕地、居民、工矿及交通用地、林地、其 他农用地、水域和未利用地等 6 种类型。

\section{1 计算公式}

要想得出一个区域的土地生态风险现 状, 就需要建立起土地利用类型与综合区域 生态风险之间的经验联系, 利用各类型的面 积比重, 构造各土地利用类型的生态风险指 数 (ecorisk index, ERI $)^{[5]}$ 。这个生态风险指 数就是用来描述一个样地内综合生态风险 的相对大小, 以便通过采样方法将景观空间 结构转化成空间化的生态风险变量, 具体计 算公式列出如下:

$$
I_{E R}=\sum_{i=1}^{n} \frac{A_{i} W_{i}}{A}
$$

式中: $\mathrm{i}$ 为各土地类型的序号; $\mathrm{Ai}$ 为样 地内第 $\mathrm{i}$ 种类型的总面积; $\mathrm{A}$ 为样地总面积;

$\mathrm{w}_{\mathrm{i}}$ 为第 $\mathrm{i}$ 种土地类型所反映出的土地生态 风险强度参数。

生态风险强度参数 $\mathrm{w}_{\mathrm{i}}$ 的确定采用层次 分析法, 但是由于传统的权重分配通常用 Delphi 专家咨询法和层次分析法(AHP)。 Delphi 法不仅对咨询专家要求较高, 而且多 轮咨询的工作量较大; 同时 AHP 采用九标 度刻划比较判断结果, 由于本文土地类型较 多, 具体操作起来比较困难, 计算也十分复 杂复杂, 基于此, 在保证科学性的前提下, 为了计算的简便, 本文采用了改进的三标度 层次分析法 ${ }^{[13]}$ 进行两级指标权重的确定, 计 算方法如下:

首先构造主观比较矩阵 $\mathrm{c}=\left[\mathrm{C}_{\mathrm{ij}}\right]_{\mathrm{n}} \mathrm{n}_{\mathrm{n}}$, 其中 
$c_{i j}=\left\{\begin{array}{l}1 \ldots \ldots \ldots . . .(\text { 指标 } i \text { 比指标 } j \text { 重要 }) \\ 0 \ldots . . \text { 指标批指标 } j \text { 同等重要 }) \\ -1 \ldots . . .(\text { 指标 } i \text { 不如指标 } j \text { 重要 })\end{array}\right.$

然后建立感觉判断矩阵 $s=\left[S_{\mathrm{ij}}\right]_{\mathrm{n}^{*} \mathrm{n}}$, 其中 $\mathrm{S}_{i j}=\mathrm{d}_{i}-\mathrm{d}_{j}$

$d_{i}=\sum_{j} c_{i j}$

最后计算客观判断矩阵 $\mathrm{R}=\left[\mathrm{r}_{\mathrm{i}}\right]_{\mathrm{n}^{*} \mathrm{n}}$, 其中

$$
\begin{aligned}
& r_{i j}=p^{\left(s_{j} / s_{m}\right)} \\
& s_{m}=\max _{i}\left(d_{i}\right)-\min _{j}\left(d_{j}\right)
\end{aligned}
$$

$P$ 为使用者定义的标度扩展值范围, 取 $p=3$, 对矩阵 $R$ 的任意一列进行归一化处理 就可以得到权重向量 $\left[\mathrm{W}_{1}, \mathrm{~W}_{2}, \ldots, \mathrm{W}_{\mathrm{n}}\right]^{\mathrm{T}}$ 。 计算最后得出各土地利用类型的综合生态 风险程度权重 (见表 1)。对各权重进行判断 矩阵的一致性检验, 得到判断矩阵的随机一 致性比率 $\mathrm{RC}=0.024<0.1$, 因此我们可以判 定该判断矩阵是令人满意的, 通过一致性检 验。

表 1. 不同土地利用类型的生态风险权重

\begin{tabular}{ccccccc}
\hline 类型 & 耕地 & 居民、工矿及交通用地 & 林地 & 其他农用地 & 水域 & 未利用地 \\
\hline 权重 & 0.101 & 0.397 & 0.050 & 0.162 & 0.033 & 0.257 \\
\hline
\end{tabular}

\section{2 数据获取}

本文计算数据是通过在津市市土地利 用现状图中利用 ArcGIS 把全市切分为众多 个 $1 \mathrm{~km} \times 1 \mathrm{~km}$ 的单元网格, 并读取出每个网
格中所包含的各种土地类型的面积, 在数据 读取过程中要将整个数据的获取覆盖到全 市的各个区域 (图 1), 实现将生态风险指数 进行空间化。最后就是利用覆盖全部工作区 的网格进行系统采样, 每个样地的都利用生

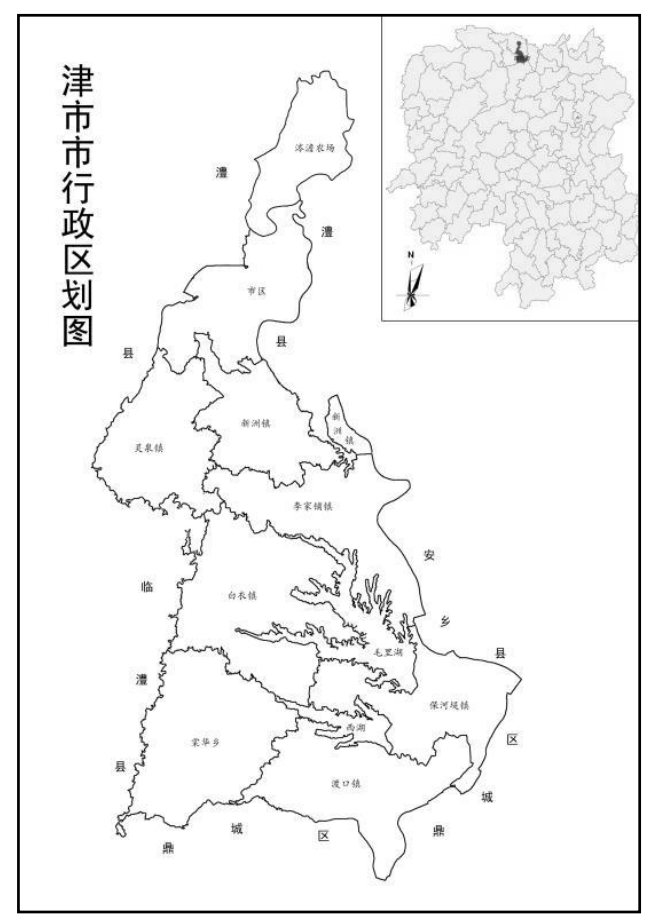

图 1. 湖南省津市市行政区划图 
态风险指数计算出一个综合性生态风险指 数值, 作为样地中心点的生态风险值, 并计 算各种土地类型所占单元格面积的相对比 例 $A_{i}$ 。

\section{3 生态风险图的获取}

综合的生态风险程度空间分布图是利 用地统计学方法完成的 ${ }^{[3,14]}$, 该方法是在生 态风险指数系统采样的基础上, 运用 ArcGIS 中的地统计分析模块(Geostatistical Analyst), 选择合适的模型进行表面模拟预测, 并检查 模型的合理性, 得出研究区域生态风险程度 空间分布图, 以直观的形式表示出了整个津 市市土地利用的生态风险空间分布状况（图 2)。
间相关性。由此采用普通克里格法对津市市 生态风险进行空间内插, 在结果检验中均值 (0.0000268)、平均标准差 $(0.003218)$ 接近 于零; 均方根 (0.00264)、平均预测标准差 (0. 00869) 也很小; 标准均方根预测误差 (0.9216) 接近于 1 , 这表明此结果的误差在 允许范围内, 保证了津市市生态风险指数空 间分布规律的准确性和可信性。

可以把全市的生态风险度可以分成 5 个 等级 (图 2), 包括高风险区、中等风险区、 一般风险区、低风险区和无风险区（本市不 存在无风险区)。其中高生态风险区主要分 布在市区, 同时李家铺乡及保河堤镇的城镇 区也是高生态风险区, 这些区域人口密集经 济活动频繁、工矿企业众多, 各类建设用地

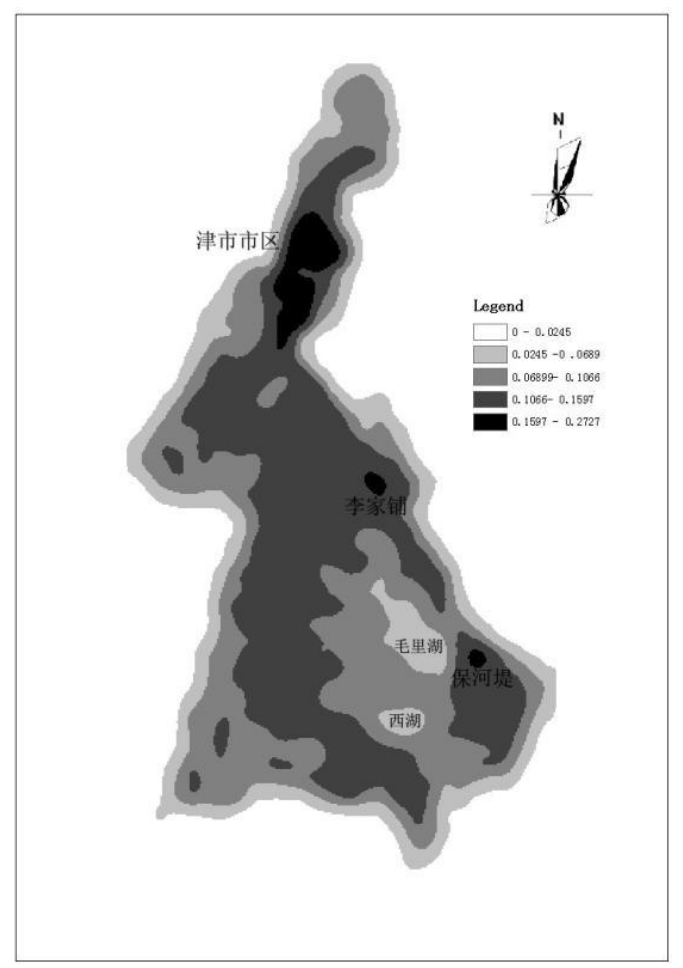

图 2. 湖南省津市市生态风险指数空间分布

\section{2. 结果与分析}

利用地理信息系统软件 ARCGIS 中提供 的地统计分析模块(Geostatistical Analyst), 得 出津市市 ERI 值接近正态分布, 数据具有空
占的比重相当的高, 因而对环境的影响十分 大, 直接导致这些区域生态风险指数高居全 市首位。就市区来说, 是典型的居民和工矿 用地密集

中等风险区主要包括市区周围的居住 
区和工业区, 各乡镇镇区所在地及人口较为 密集、交通方便、有一定工业分布的区域, 在全市各个乡镇皆有分布, 这一区域不管是 从人类活动还是经济密度上来说都是处于 第二梯队层次, 这样也就使其的生态风险指 数为中等。这一区域的新洲镇、蔡家河都已 经纳入到了津市市城区规划范围内, 一些城 市功能也开始向其转移, 人口密度的增加和 市区产业的转移将在今后一段时间内使这 一区域的面临着更高的生态风险压力; 而这 一区域的灵泉镇、白衣镇、棠华乡随着全市 城市化的发展和城镇体系的建设, 在加大招 商引资力度的背景下也同样面临着越来越 高的生态风险压力。总体来说, 这一区域在 发展过程中一定要注意好对生态环境的保 护和土地资源的合理利用, 切忌片面追求经 济效益的行为, 同时要从现在开始治理出现 的各种环境问题, 考虑发展过程中所存在的 潜在问题, 以保证实现整个区域的良性发展。

一般风险区主要分布在各个乡镇的人 口密集区以外, 本区的经济发展结构以农业 生产为主, 本区的耕地、林地分布较多, 高 于全市平均水平, 人口低于全市平均水平, 这一区域虽然无论从人口还是从工业的发 展来看, 都对生态风险影响不高, 但是大力 发展农业破坏了植被, 导致水体污染, 还进 行了大量的围艮活动致使区域湿地资源减 少, 改变了原来的生态条件。因此应该加强 此区域的生态修复工作; 提高耕地质量, 改 善农业生产条件, 减少对水体的污染; 加大 退耕还湖力度, 恢复原有湿地面积, 增加区 域的物种多样性; 继续坚持退耕还林, 增加 林地面积, 改善土地生产环境; 搞好未利用 地的开发利用。

低风险区主要分布在嘉山风景区、毛里 湖、西湖和与其他县市交界的区域。本区域 内的各种人类活动影响较小, 对生态环境的 影响甚微, 其生态风险指数值低。其中本区 域与其他县市的交界区域经济落后, 人烟稀 少, 从而生态环境质量较高, 而嘉山风景区 和两大湖由于地类的单一性也保持了较好 的生态环境。尽管本区生态风险指数较低, 但是考虑的社会经济的发展所带来的潜在 威胁, 要特别注意风景区里的经济活动和湖
泊的网箱养殖, 由于西湖是津市的主要渔场、 毛里湖是津市重要湿地区, 因此一定要防止 这些区域的环境污染, 并治理好现存问题, 保持较高生态环境质量。

\section{3. 结论与讨论}

从 ERI 空间分布格局来看, 全市的高土 地生态风险区主要分布在城镇和主要交通 干线沿线, 这与现实情况相吻合。这种分布 格局充分说明人类的集聚和沿着交通干道 的发展模式对区域土地生态风险程度的提 高起到了关键的推动作用。同时 ERI 值也呈 现出从中心城区向远郊逐渐降低的变化趋 势, 聚集化程度较低区域的环境水平明显优 于城市化区域。

生态风险评价将风险的思想和概念引 入到生态环境影响评价中, 而与一般生态影 响评价的重要区别在于强调不确定性因素 的作用, 在整个分析过程中要求对不确定性 因素进行定性和定量化研究, 并在评价结果 中体现风险程度。生态风险指数的大小只是 相对于生态问题可能发生的综合性概率量 度, 因而无法对具体的、针对性的生态保护 决策提供直接依据。但是根据生态风险程度 高低程度, 应该在高生态风险区域强化以提 高土地生产功能、环境功能为重点的土地基 础设施建设, 加强工业及城镇用地的生态建 设, 高生态风险区域无疑是今后生态保护工 作需要重点关注的区域; 而中等程度生态风 险区则有可能在不久的将来成为高生态风 险区, 因此需要重点加以规划和治理; 一般 生态风险区和低生态风险区域的生态建设 也是不容忽视的问题。总的来说, 在全市范 围内提高人们对生态环境保护的认识, 加大 环境保护与生态建设力度, 倡导有利于可持 续发展的经济发展方式、生产方式和消费方 式 ${ }^{[15]}$, 努力把津市市建设成为结构合理、功 能健全、环境优美、经济效益不断增长、人 们生活质量不断提高的小康市域。

\section{参考文献}

[1] McDanielsT, et al. Characterizing perception of ecological risk. Risk Anal, 1995, 15(5):575-588. 
[2] 李国旗,安树青,陈兴龙, 等.生态风险研 究述评.生态学杂志, 1999, 18(4): 57-6 4.

[3] 刘勇,邢育刚,李晋昌.土地生态风险评价 的理论基础及模型构建.中国土地科学, 2012, 26(6):20-25.

[4] 谢正峰. 中国 “土地生态安全”与 “土 地生态风险”研究比较.云南地理环境研 究,2012,24(5): 12-18.

[5] 殷浩文.生态风险评价.上海:华东理工大 学出版社, 2001.

[6] 马彩虹. 陕西黄土台塬区土地生态风险 时空差异性评价.水土保持研究,2014, 2 1(5): 216-220.

[7] 任志远, 孙艺杰, 吴林䈗.1990-2012 年 榆林市土地生态风险综合评价.中国生 态农业学报,2017,25(5):656-664.

[8] 傅丽华. 基于景观结构的长株潭核心区 土地生态风险调控研究.长沙, 湖南师范 大学, 2012.

[9] 陈鹏,潘晓玲.干旱区内陆流域区域景观 生态风险分析-以阜康三江河流域为例. 生态学杂志,2003,22(4):116-120.
[10] 李梅,朱红旗,蔡永立. 景观生态风险信息 系统的概念、方法和步骤. 国土与自然资 源研究,2002(2):42-43.

[11] 陈浩,周金星,陆中臣, 等. 荒漠化地区生 态安全评价-以首都圈怀来为例. 水土保 持学报,2003,17 (1) :58-62.

[12] 虞燕娜, 朱江, 吴绍华, 等. 多风险源驱动 下的土地生态风险评价一一以江苏省 射阳县为例. 自然资源学报,2016, 31(8): 1264-1273.

[13] 张航,谢传礼,高俊,等. 基于三标度法的 层次分析法在储层分类评价中的应用. 重庆科技学院学报(自然科学版),2015,1 $7(6): 30-32$.

[14] 彭文君,舒英格. 基于 GIS 的石漠化山 区县域土地利用空间变化的生态风险 测度.水土保持研究,2018, 25(1): 342-3 48.

[15] 毛德华,李姣,邹君,等.经济发展方式的 生态转型. 北京:经济日报出版社, 2015 . 